\title{
Extracellular Protease Activation of Chemotherapeutics from Hydrogel Matrices: A New Paradigm for Local Chemotherapy Jovita R. Tauro ${ }^{\dagger}$ and Richard A. Gemeinhart ${ }^{t^{*}}$ Departments of Biopharmaceutical Sciences ${ }^{\dagger}$ and Bioengineering ${ }^{*}$, The University of Illinois, Chicago, Illinois 60612-7231. \\ rag@uic.edu
}

\section{MATERIALS AND METHODS}

The matrix metalloprotease (MMP-)sensitive peptide substrate, CGLDD, and the expected cleaved fragment, LDD, were synthesized by Research Resources Center at the University of Illinois at Chicago with the N-terminal amine acylated. MMPs were purchased from Calbiochem. PEGDA $\left(\mathrm{M}_{\mathrm{n}, \text { PEG }}=574\right.$, PEG(574)DA)was purchased from Sigma Aldrich Chemical company (Milwaukee, WI). PEGDA ( $M_{n}$, PEG $=4000$, PEG(4000)DA) was purchased from Polysciences Inc. (Warrington, PA). All remaining chemicals were purchased from Fisher Scientific (Fairlawn, NJ) and used without further purification unless specified.

\section{Preparation and Characterization of Hydrogels}

The MMP-sensitive peptide substrate $(2 \mu \mathrm{mol})$ was dissolved in water and mixed with PEG(574)DA $(100 \mathrm{mM})$ or PEG(4000)DA (15.9 mM) and stirred overnight. Michael addition of the acrylate group to the sulfhydryl group on cysteine ${ }^{1}$ was confirmed using Ellman's reagent (Pierce, Milwaukee, WI) to quantify number of free sulfhydryl groups. ${ }^{2}$ PEGDA-peptide solutions (or peptide-free PEGDA at the concentrations listed above) were polymerized without further purification between glass slides to form sheets of hydrogels using ammonium persulfate and $\mathrm{N}, \mathrm{N}, \mathrm{N}, \mathrm{N}$-tetramethylethylenediamine as the initiator and the free radical stabilizer. Hydrogels were cut into $6 \mathrm{~mm}$ diameter wafers using a biopsy punch and washed repeatedly in phosphate buffered saline (PBS) to remove unpolymerized monomers and, finally, allowed to dry partially in a vacuum oven. Cisplatin was aquated at $\mathrm{pH} 7.4$ using silver nitrate $^{3}$ and reacted overnight with hydrogels. Hydrogels containing the peptide were washed to remove 
excess cisplatin. Hydrogels were also prepared without the peptide with cisplatin entrapped by soaking hydrogels as stated for complexation above. Hydrogels were analyzed for cisplatin content using ophenylenediamine (OPDA). ${ }^{4}$ Hydrogels entrapped slightly less cisplatin $\left(0.32 \pm 0.02 \mu \mathrm{g} / \mathrm{mm}^{3}\right)$ in the low molecular weight PEGDA than high molecular weight PEGDA hydrogels $\left(0.43 \pm 0.05 \mu \mathrm{g} / \mathrm{mm}^{3}\right)$. Complexed cisplatin was nearly equivalent in the two hydrogels with low molecular weight PEGDA hydrogels containing $0.12 \pm 0.02 \mu \mathrm{g} / \mathrm{mm}^{3}$ and high molecular weight PEGDA hydrogels containing $0.16 \pm 0.02 \mu \mathrm{g} / \mathrm{mm}^{3}$

\section{Cell Culture and MMP activity}

The malignant glioma cell line (U-87 MG, ATTC \#HTB-14) was grown and maintained in Eagles Minimum Essential Media with 10\% fetal bovine serum, 1\% Penicillin/Streptomycin, sodium pyruvate (110mg/L), L-Glutamine (292 mg/L), and nonessential amino acids. Cells were cultured at $37^{\circ} \mathrm{C}$ in $5 \%$ $\mathrm{CO}_{2}$.

\section{Cisplatin Release}

Cisplatin release from the hydrogels was determined at $37{ }^{\circ} \mathrm{C}$ in a buffer containing Tris- $\mathrm{HCl}(50$ $\mathrm{mM}), \mathrm{NaCl}(0.2 \mathrm{M}), \mathrm{CaCl}_{2} \cdot 2 \mathrm{H}_{2} \mathrm{O}(10 \mathrm{mM}), \mathrm{Brij}-35(0.05 \%)$ and $\mathrm{ZnSO}_{4} \cdot 7 \mathrm{H}_{2} \mathrm{O}(50 \mu \mathrm{M})$ in the presence and absence of MMPs (10 nM). OPDA was used for cisplatin analysis. These profiles were compared to the release of cisplatin entrapped in the hydrogels without complexation; no peptide was present in the hydrogel for cisplatin entrapped studies which act as a diffusional release control.

\section{In vitro cisplatin Activity}

Hydrogels were incubated with the cells in supplemented serum free media for 24 hours to determine the activity of the hydrogel-cisplatin complex devices. MMP (10 nM) was added to the media to supplement the MMPs expressed by the cells and thus accentuate the amount of cisplatin released. Although the exact concentration of MMP in tumors varies significantly with stage and other factors, ${ }^{5}$ this concentration is similar to that in culture media after cell culture (U-87 MG cells) for 48 hours. $^{6}$ Activity of the hydrogel-cisplatin complex devices was also studied in the absence of added MMPs 
because MMPs are known to be expressed by U-87MG cells. ${ }^{7}$ Cell viability with respect to the untreated control was calculated using a modified MTT assay (Cell Titer 96® Aqueous One solution Cell Proliferation Assay; Promega; Madison, WI). ${ }^{8}$

\section{REFERENCES}

(1) Heggli, M.; Tirelli, N.; Zisch, A.; Hubbell, J. A. Michael-type addition as a tool for surface functionalization. Bioconjugate Chemistry 2003, 14, 967-973.

(2) Ellman, G. L. Tissue sulfhydryl groups. Archives of Biochemistry and Biophysics 1959, 82, 7077.

(3) Gianasi, E.; Buckley, R. G.; Latigo, J.; Wasil, M.; Duncan, R. HPMA copolymers platinates containing dicarboxylato ligands. Preparation, characterization and in vitro and in vivo evaluation. Journal of Drug Targeting 2002, 10, 549-556.

(4) Golla, E. D.; Ayres, G. H. Spectrophotometeric determination of platinum with ophenylenediamine. Talanta 1973, 20, 199-210.

(5) Powell, W. C.; Matrisian, L. M. Complex roles of matrix metalloproteinases in tumor progression. Current Topics in Microbiology and Immunology 1996, 213, 1-21.

(6) Tauro, J. R.; Gemeinhart, R. A. Matrix Metalloprotease Sensitive Hydrogels for Glioblastoma Multiforme Treatment. Proc. Int. Symp.Control. Rel. Bioactive Mater. 2005, 32, 258.

(7) Bae, M.; Cho, S.; Song, J.; Lee, G. Y.; Kim, K.; Yang, J.; Cho, K.; Kim, S. Y.; Byun, Y. Metalloprotease-specific poly(ethylene glycol) methyl ether-peptide-doxorubicin conjugate for targeting anticancer drug delivery based on angiogenesis. Drugs under experimental and clinical research 2003, $29,15-23$. 
(8) Paull, K. D.; Shoemaker, R. H.; Boyd, M. R.; Parsons, J. H.; Risbood, P. A.; Barbera, W. A.; Sharma, M. N.; Baker, D. C.; Hand, E.; Scudiero, D. A.; Monks, A.; Alley, M. C.; Grote, M. The synthesis of XTT- a new tetrazolium reagent that is bioreducible to a water soluble formazan. Journal of Heterocyclic Chemistry 1988, 25, 911-914. 